\title{
BRUNNER, Horst, Die Wahrnehmung und Darstellung von Kriegen im Mittelalter und in der Frühen Neuzeit
}

\section{Claire Gantet}

\section{OpenEdition}

\section{Journals}

Édition électronique

URL : http://journals.openedition.org/ifha/1266

DOI : $10.4000 /$ ifha. 1266

ISSN : 2198-8943

\section{Éditeur}

IFRA - Institut franco-allemand (sciences historiques et sociales)

\section{Référence électronique}

Claire Gantet, «BRUNNER, Horst, Die Wahrnehmung und Darstellung von Kriegen im Mittelalter und in der Frühen Neuzeit », Revue de l'IFHA [En ligne], Date de recension, mis en ligne le 01 janvier 2001, consulté le 22 septembre 2020. URL : http://journals.openedition.org/ifha/1266 ; DOI : https://doi.org/10.4000/ ifha. 1266

Ce document a été généré automatiquement le 22 septembre 2020.

(C)IFHA 


\title{
BRUNNER, Horst, Die Wahrnehmung und Darstellung von Kriegen im Mittelalter und in der Frühen Neuzeit
}

\author{
Claire Gantet
}

1 Fruit du travail de l'équipe pluridisciplinaire «L'image de la guerre en mutation, de la fin du Moyen Âge à l'époque moderne » constituée à l'université de Wurtzbourg en 1994, et issu d'un colloque tenu du 14 au 17 octobre 1998, ce recueil d'articles s'assigne cinq buts : éclairer les buts de guerre perçus par les contemporains des XVe et XVIe s., d'après l'exemple des faides des évêques de Wurtzbourg ; analyser la représentation et l'appréciation de la guerre dans les chroniques allemandes; étudier l'image de la guerre dans la littérature allemande; présenter l'image de la guerre en Europe centrale ; enfin, exposer les traités techniques et les manuscrits illustrés du Moyen Âge et de l'époque moderne. Le foisonnement de ces questionnements nuit sans doute à la clarté de la problématique générale, d'autant que l'ouvrage est dénué de conclusion.

Dans cet ensemble touffu, quelques thématiques se dégagent néanmoins. Les guerres envisagées sont d'abord souvent des guerres de la périphérie du Saint-Empire : les conflits dans les territoires de l'Ordre teutonique en Pologne-Lituanie entre le XIVe et le XVIe s. (en particulier la guerre de Livlande de 1558 à 1582) et l'intérêt qu'ils soulèvent dans l'Empire, exposés par J. WENTA et H. GRALA, et le mouvement de solidarité entre des états des territoires patrimoniaux des Habsbourg autour de la demande d'argent suscitée par l'empereur Matthias en 1615 pour porter la guerre aux Turcs, analysé par I. AUERBACH. Mais ce sont surtout des guerres civiles, voire - et le changement d'échelle est intéressant - des guerres urbaines : les heurts de la bourgeoisie de Wurtzbourg et de son évêque entre 1247 et 1400, nourris par les ambiguïtés des privilèges royaux ou pontificaux ainsi que par la complication des droits ancestraux, observés par H. LONSDORF. En envisageant les présentations littéraires des sièges urbains sur le long terme, et les inflexions vers une dénonciation plus sévère au temps d'Érasme et de la Réforme, J. RETTELBACH aborde la question du travail littéraire. De fait, l'intérêt essentiel du recueil réside sans doute dans l'étude de la 
représentation de la guerre dans les chroniques et la littérature allemandes (si l'on fait abstraction de l'exposé liminaire de K. HIRAO sur la tradition japonaise des poèmes rédigés à l'approche de la mort). J. HAMM souligne combien la guerre des paysans a été une rupture aussi pour la littérature. Face aux catholiques qui diffusent l'image d'un Luther seditiosus, les luthériens tentent de se démarquer des paysans en jetant la pierre sur Thomas Müntzer ; chez certains auteurs néo-latins, tels Camerarius, la forme bucolique et humaniste permet toutefois de développer une pensée autonome et critique. Quant à E. KLECKER, elle montre combien les panégyriques et la propagande au temps de la guerre de Trente Ans, et en particulier de la campagne de Gustave Adolphe, ont été imprégnés de référence à la Pharsale de Lucien. Deux articles lient ces approches littéraires à une étude sociale. $\mathrm{R}$. BACH et $\mathrm{C}$. HRUSCHKA relèvent les différences entre les chroniques rédigées par les clercs et celles composées par des membres de la basse noblesse : face à l'attitude observatrice et critique des premiers, les seconds ont une vision à la fois plus pratique et plus idéalisée de la guerre. P. MONNET s'attache aux chroniques de Francfort-sur-le-Main pour montrer comment l'étude de la diplomatie conduite au niveau urbain s'intègre dans des représentations de l'espace, s'articule à un cérémoniel politique et à une politique de la mobilité, entreprise avec succès au moyen d'un large éventail de moyens de communication et de signes symboliques; c'est ainsi que la diplomatie contribue à accentuer la hiérarchie urbaine naissante.

3 Par l'accent mis sur les sources littéraires (au sens large), cet ouvrage peut s'inscrire dans un renouvellement de l'histoire militaire, qui, après avoir été envisagée d'un point de vue événementiel puis social, se tourne vers l'histoire culturelle. C'est dire son intérêt, malgré le foisonnement des thématiques. 